LBNL-52251

\title{
VACUUM ARC DEPOSITED DLC BASED COATINGS
}

\author{
O.R. MONTEIRO*, M.P. DELPLANCKE-OGLETREE** \\ * Lawrence Berkeley National Laboratory University of California \\ Berkeley, California 94720, USA \\ ** Industrial Chemistry, Université Libre de Bruxelles, \\ Brussels 1050, Belgium
}

\begin{abstract}
The great interest in the use of diamond-like carbon (DLC) films as a coating material is justified by the superior wear resistance and hardness, chemical inertness, and very low friction coefficients of these coatings. Vacuum arc deposition is well suited to prepare superhard films with high $\mathrm{sp}^{3} / \mathrm{sp}^{2}$ ratios. However, the high level of internal stresses originating during growth prevents the deposition of thick films, and their hardness makes it difficult for DLC layers to comply with substrate deformations. In order to overcome these limitations, different approaches are possible. Multilayer structures are one means to maintain the surface mechanical properties of the DLC while relieving the internal stresses. Another possibility is to dope the DLC films in order to reduce the internal stress and to stabilize the desirable $\mathrm{sp}^{3}$ bonds to higher temperatures. At higher doses of dopants, the formation of nanocrystals is possible and the properties of the coatings change drastically. All these approaches were investigated on films prepared by cathodic arc and a synthesis of the results is presented here.
\end{abstract}

\section{Introduction}

In response to the challenges of implementing diamond-like carbon (DLC) into several applications, different strategies have been developed in order to enhance their performances. Addition of alloying elements such as refractory metals [1], silicon [24], nitrogen and fluorine was extensively investigated. Incorporation of such elements typically leads to improvements in some properties at the expense of others.

The formation and properties of nanocomposite, functionally graded layers and multilayers involving DLC has also been the subject of extensive work [5-6]. The results are very promising [7].

Stresses can reach values higher than $10 \mathrm{GPa}$ in pure non-hydrogenated DLC [8], and about $3 \mathrm{GPa}$ in hydrogenated DLC [2]. If there is a general acceptance in the literature on the effect of alloying elements on the reduction of internal stress, the results 
concerning other properties are not as generally accepted. For example, reports on the influence of the silicon concentration on the hardness of the DLC doped films are contradictory $[2,9,10]$. Most of the work on silicon additions to DLC has involved hydrogenated films. The effect of tungsten and titanium additions on the mechanical is highly dependent on the concentration of the alloying element that induces changes in the structure of the films.

Many parameters such as proportion of the different layers, the structure of the inferfaces control the properties of multilayers. A comparison of the properties of coatings prepared by different techniques is thus rather difficult.

The work presented here focuses on non-hydrogenated DLC based coatings prepared by filtered cathodic arc and will briefly summarized results on mechanical properties and structure of silicon and tungsten doped layers, TiC-DLC nanocomposites and TiCDLC multilayers.

\section{Experimental procedure}

\section{II.1. DEPOSITION}

The various coatings were prepared using two filtered cathodic plasma sources and a pulsed bias voltage applied to the substrate. Depending on the desired structure of the coatings (doped DLC, multilayers, nanocomposite), the two sources were triggered simultaneously or successively. In all cases, one source was fitted with a graphite cathode and the other with the addition element cathode: Silicon, titanium or tungsten. For the doped and nanocomposite layers, the composition was controlled by varying the duration of the pulses in each source. During each plasma pulse a fraction of a monolayer was deposited. No layering was observed in these conditions. For the multilayers, the carbon source was working by itself for the deposition of the pure DLC components. The titanium source was added for the synthesis of the $\mathrm{TiC}_{\mathrm{x}}$ component of the multilayers.

A pulsed bias voltage was applied to the substrate during each arc pulse. The pulse duration of the sources varied between 0.5 and $10 \mathrm{~ms}$. The arc frequency was $1 \mathrm{~Hz}$ and pulsed bias voltage of $-100 \mathrm{~V}$ was applied to the substrate with alternating on-periods of $2 \mu \mathrm{s}$ and off-periods of $6 \mu \mathrm{s}$. To obtain a diffuse interface between the substrate and the coatings or between the different layers composing the coatings, a higher bias voltage of $-2000 \mathrm{~V}$ was imposed for a short period before switching to $-100 \mathrm{~V}$.

\section{II.2. CHEMICAL AND STRUCTURAL CHARACTERIZATION}

Quantitative chemical composition of the deposited coatings was obtained by Rutherford Backscattering Spectroscopy using a $1.8 \mathrm{keV} \mathrm{He}^{+}$beam. X-Ray photoelectron spectroscopy (XPS) and Auger Electron Spectroscopy (AES) were used to characterized the bonding in the films and the depth distribution. Transmission 
electron microscopy was used to characterize the morphology and structure of the films, TEM was carried out in a Phillips CM200 with a PEELS system and a Topcon 002B with point resolution of $0.19 \mathrm{~nm}$ at $200 \mathrm{kV}$.

\section{II.3. MECHANICAL AND TRIBOLOGICAL CHARACTERIZATION}

Hardness and elastic modulus of the films were determined by nanoindentation using a Hysitron Picoindenter. The hardness was evaluated from the residual impression of the indenter whereas the modulus was evaluated from the slope of the load-unload curve at the beginning of the unloading process [11]. A Hysitron Triboscope was used to determined the friction coefficient. It was determined using a single-pass scratch test. Ball on disk wear tests were performed to evaluate the macroscopic wear resistance of the layers using a CSEM apparatus. The test were performed in 50\% relative humidity, with a $2 \mathrm{~N}$ load, a $6 \mathrm{~mm}$ in diameter alumina ball at $0.2 \mathrm{~m} / \mathrm{s}$ speed.

\section{Results and discussions}

\section{III.1. SILICON DOPED AND TUNGSTEN DOPED LAYERS}

The Si-content of the DLC:Si films used in this work are 3 at $\%, 5$ at $\%$ and 6 at $\%$ as determined by RBS. The W-content of the DLC-W films varied between 1 and 10 at $\%$. The film composition and structure result from a balance between the indicidant ion currents from the two plasma sources and the sputtering rates of the individual elements due to the incident energetic $\mathrm{Si}^{\mathrm{n+}}$ or $\mathrm{W}^{\mathrm{n}+}$ and $\mathrm{C}^{+}$ions. The mean charge state of the $\mathrm{Si}^{\mathrm{n+}}$ ions generated by the cathodic arc source is 1.4 while the mean chage state of the $\mathrm{W}^{\mathrm{n}+}$ ions is higher than 3 . This is extremely important for the mean energy transferred to the growing film. It is dependent on the proportion of the elements incorporated in the films all other conditions remaining constant. It is known that the properties of undoped DLC depends strongly on the energetics of the deposition. However, for low ratio of addition element in the mixed plasma stream the final effect of the difference in energy transfer should be relatively small especially in the case of silicon.

For both system, the films are totally amorphous in the range of concentration considered here. The $\mathrm{sp}^{3}$ content increases with the incorporation of silicon in the films [10], the highest ratio being obtained for 3 at $\%$. The hardness values of DLC/Si films obtained at several loads are shown in figure 1 . The values given in this figure are not corrected for the deformation of the diamond indenter. The "real" hardness is probably slightly lower than the values that are quoted. The hardness of undoped DLC films prepared in similar conditions is of the order of $72 \mathrm{GPa}$. The addition of silicon induces a hardness decrease but it is accompanied by a large decrease of internal stress.

A similar behavior is observed for W:DLC films as shown in figure $2 a$ and $b$. The addition of 1 at $\%$ of tungsten reduces the stress by a factor of three but decreases the hardness only by $15 \%$. In both systems, the best compromise between reduced stresses and hardness is obtained at low concentration of the addition element. The weaker Si-C 
and W-C bonds could be responsible of the reduction of the stress and of the hardness. These bonds also stabilize the $\mathrm{sp}^{3}$ configuration of the carbon atoms. The very strong effect of tungsten could also be related at high concentration to the modification of the $\mathrm{sp}^{3} / \mathrm{sp}^{2}$ ratio resulting from the large energy input per $\mathrm{W}$ atom.

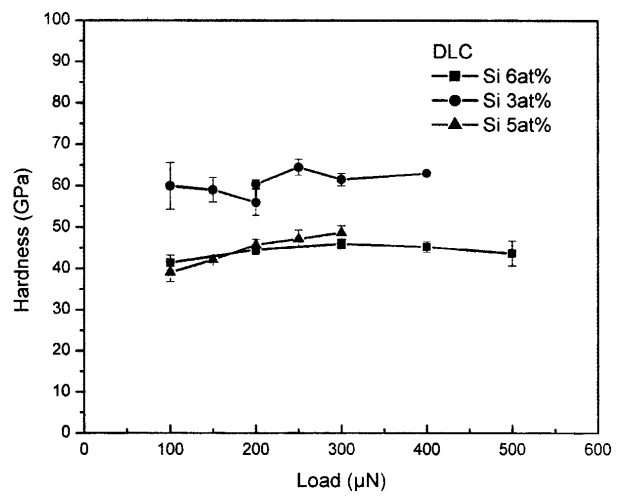

figure 1: Hardness of the DLC:Si films obtained at several loads

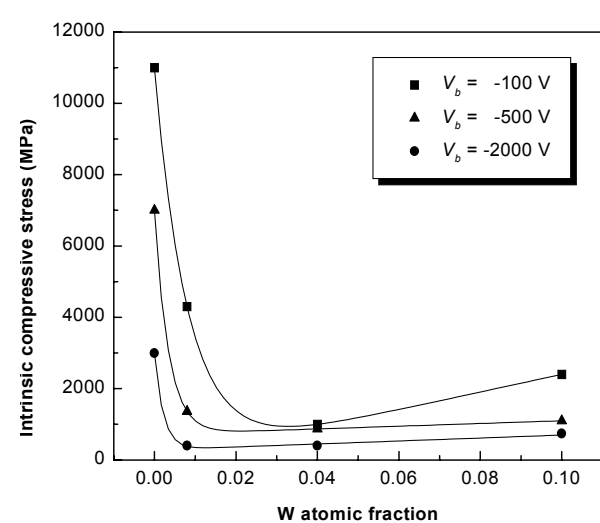

(a)

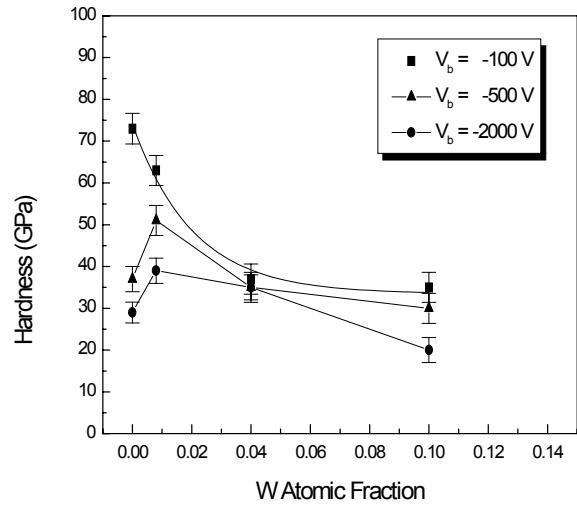

(b)

Figure 2: variation of (a) internal stress and (b) hardness with the W-content in DLC:Z films

\section{III.2. $\mathrm{TiC}_{\mathrm{x}}$-DLC MULTILAYERS}

Figure 3 presents the structure of three multilayers based on $\mathrm{TiC}_{\mathrm{x}}$ and pure $\mathrm{DlC}$ components. Each interface was deposited at a bias voltage of $-2000 \mathrm{~V}$ while the bulk is deposited at $-100 \mathrm{~V}$ for ensuring a good adhesion between the different components of the film. Figure 4 gives the hardness and elastic modulus of the same layers at different loads. None of these values was corrected for the deformation of the indenter tip. This deformation is responsible of the abnormally high value of the registered hardness The decrease of hardness as a function of load reflects the hardness variation 
with indentation depth. The contribution of $\mathrm{TiC}_{\mathrm{x}}$ layers, having a lower hardness than pure DLC, increases with the indentation depth and thus reduces the total hardness of the system.

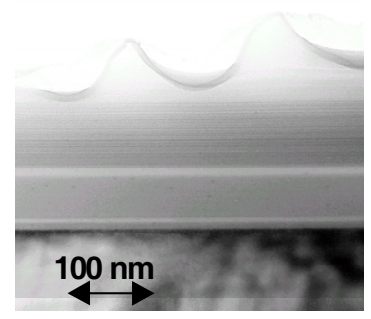

(a)

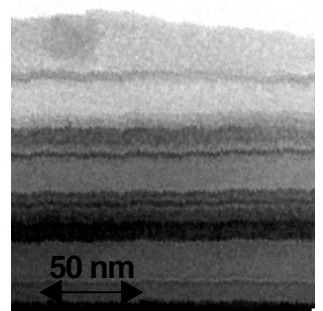

(b)

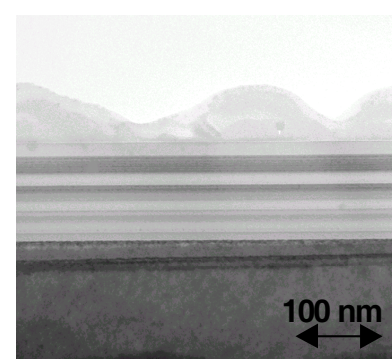

(c)

figure 3: TEM of multilayers (a) DLC-TiC - DLC-Si, (b) DLC-TiC - DLC-TiC ${ }_{\mathrm{x}}-\mathrm{DLC}-\mathrm{Si}$ and (c) DLC-TiC ${ }_{\mathrm{x}}-$ DLC-TiC $\mathrm{x}$-DLC-TiC $\mathrm{x}_{\mathrm{x}}$-DLC-Si

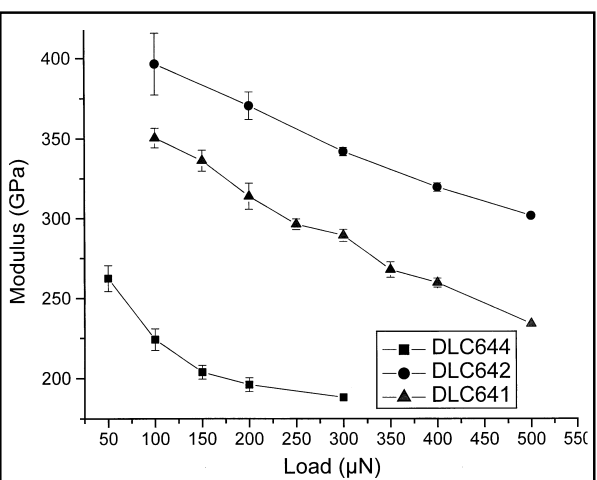

(a)

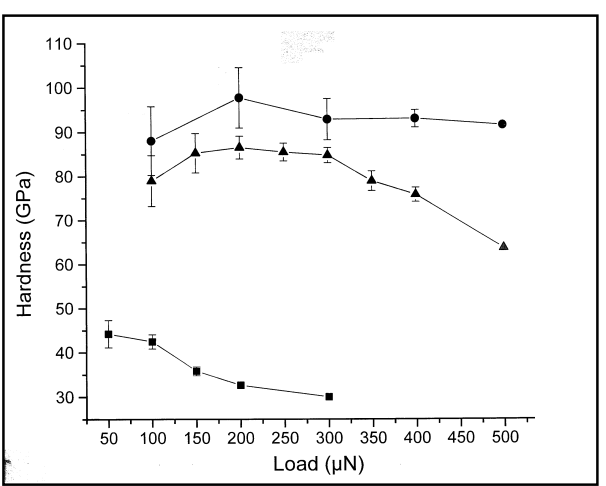

(b)

Figure 4: variation of the (a) elastic modulus and (b) hardness of the multilayers: triangle $=$ DLC-TiC $\mathrm{x}_{\mathrm{x}}-\mathrm{DLC}-$ $\mathrm{Si}$, dots $=\mathrm{DLC}_{\mathrm{TiC}}-\mathrm{DLC}-\mathrm{TiC}_{\mathrm{x}}-\mathrm{DLC}-\mathrm{Si}$ and squares $=$ DLC-TiC $\mathrm{C}_{\mathrm{x}}-$ DLC-TiC $\mathrm{x}-\mathrm{DLC}-\mathrm{TiC}_{\mathrm{x}}-\mathrm{DLC}-\mathrm{Si}$

The elastic modulus follows a similar trend. The strong reduction of the hardness and modulus for the 7 layers film is due to the high proportion of interfaces in this film. The interfaces are soft because the $\mathrm{sp}^{2}$ content is high for films deposited with a $2000 \mathrm{~V}$ bias. The friction coefficient measured during a single-pass nanoscratch reflects the penetration of the indenter in the different layers when the load is increased as shown on figure 5 . The step noticed when the normal load reach a value of $100 \mu \mathrm{N}$ is probably due to the penetration of the indenter in the second layer. This layer is softer and has another composition. The friction coefficient of $\mathrm{TiC}$ is higher than for DLC. The step increase in partially due to the change of contact nature but also to an increase of the plowing contribution to the friction coefficient.

The value of the friction coefficient obtained at the nanometric scale is similar to those measured during macroscopic wear tests. In those tests, a step-like variation of the 


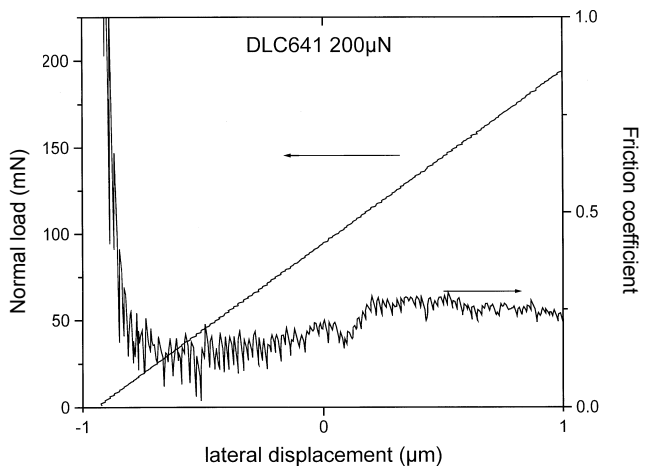

Figure 5: variation of the friction coefficient during a single-pass nanoscratch in the DLC-TiC $\mathrm{x}_{\mathrm{x}} \mathrm{DlC}$ film . The normal load increases linearly from left to right

friction coefficient is also observed as the number of rotations is increasing. The contact of the alumina ball with the $\mathrm{TiC}_{\mathrm{x}}$ layer is probably also responsible of this sudden increase. In this conditions, the normal load is constant but the top DLC layer is progressively wearing out with the $\mathrm{TiC}_{\mathrm{x}}$ layer showing up in the center of the track.

For the $\mathrm{TiC}_{\mathrm{x}}$-DLC system studied here, the best compromise seems to be a 5 layer films. The hardness and elastic modulus of this film are high and its wear behavior is excellent.

\section{Conclusions}

By doping, forming nanocomposite layers or alternating DLC and carbide containing layers, it is possible to tune the mechanical properties of DLC based coatings and to overcome the main disadvantages of pure DLC films. The proportion of the alloying element is critical for the structure of the coatings and for their properties. At low concentrations, the amorphous structure is mainly maintained, the stress reduction is significant and the hardness remains relatively high. At higher concentrations, attention must be paid to the mean charge state of the alloying element because it can modify the energy transferred to the growing film and thus indirectly change the $\mathrm{sp}^{3}$ to $\mathrm{sp}^{2}$ ratio. The alloying element can form a separate phase giving rise to a nanocomposite structure. The parameters controlling the mechanical properties in those films differ from those observed in the doped layers.

The proportion of "soft" interface and the relative thickness of the DLC and $\mathrm{TiC}_{\mathrm{x}}$ layers are the key factors for the mechanical properties of the multilayers.

\section{Acknowledgements}

The authors would like to thank the Computer Mechanics Laboratory at the University of California, Berkeley and the F.N.R.S for continuous support 


\section{References}

1. Delplancke-Ogletree, M.P. and Monteiro, O.R. (1998), Surface and Coatings Technology 108109, 484-488

2. Baia-Neto, A.L., Santos, R.A., Freire Jr, F.L., Camargo Jr, S.S., Carius, R., Finger, F., and Beyer, Z. (1997), Thin Solid Films 293, 206-211

3. Shi, J.R., Shi, X., Sun, Z., Liu, E., Yang, H.S., Cheah, L.K., and Jin, X.Z. (1999), J. Phys.: Condens. Mater. 11, 198-203

4. Lee, C.S., Lee, K.R., Eun, K.Y., Yoon, K.H., and Han, J.H. (2002), Diamond and Related Materials 11, 198-203

5. Voevodin, A.A., and Zabinski, J.S. (1998), Diamond and Related Materials 7, 463-467

6. Miyoshi, K., Pohlchuck, B., Street, K.W., Zabinski, J.S., Sanders, J.H., Voevodin, A.A., and Wu, R.L.C. (1999), Wear 115-119, 65-73

7. Delplancke-Ogletree; M.P., and Monteiro; Multilayer paper

8. Monteiro, O.R., Ager III, J.Z., Lee, D.H., Yu Lo, R., Walter, K.C., and Natasi, M. (2000), J. Appl. Phys. 88(5), 2395-2399

9. Zhao, J.F., Lemoine, P., Liu, Z.H., Quinn, J.P., Maguire, P., and McLaughlin, J.A. (2001), Diamond and Related Materials 10, 1070-1075

10. Monteiro, O.R., and Delplancke-Ogletree, M.P. (2002), Surface and Coatings Technology, accepted

11. Oliver, W.C., and Pharr, G.M. (1992), J. Materials Res. 7(6), 1564-1583 